\title{
Process flowsheet analysis of pervaporation-based hybrid processes in the production of ethyl tert-butyl ether
}

\author{
Authors: Adham Norkobilov ${ }^{(1,2)}$, Daniel Gorri ${ }^{(1)}$, Inmaculada Ortiz* ${ }^{(1)}$ \\ ${ }^{(1)}$ Departamento de Ingenierías Química y Biomolecular, Universidad de Cantabria, Av. \\ de Los Castros s/n, 39005 Santander, Spain \\ (2) Tashkent chemical-technological institute, 32, Navoi str., Tashkent, Uzbekistan, p/o:
}

100011

*To whom correspondence should be addressed.

Submitted to Journal of Chemical Technology and Biotechnology

\begin{abstract}
BACKGROUND: The manufacturing process of ethyl tert-butyl ether (ETBE) involves the separation of ETBE, mixed C4 hydrocarbons and unreacted ethanol. Unfortunately, the unreacted ethanol forms azeotropic mixtures with ETBE that are difficult to separate by distillation. One of the alternative methods to overcome this limitation is the application of hybrid distillation-pervaporation processes with alcohol-selective membranes.

RESULTS: Simulation tasks were carried out with the process simulation software Aspen Plus and the results of alternative process flowsheets that result from the relative location of the separation technologies (for a target product purity) have been compared on the basis of the required membrane area and energy consumption. Thus, in the case of study analyzed 7 PV modules located on a side-stream withdrawal, with a total membrane area of $210 \mathrm{~m}^{2}$, are required to obtain $6420 \mathrm{~kg} \mathrm{~h}^{-1}$ de ETBE with a purity of $95.2 \mathrm{wt} \%$. The retentate stream is returned to the column while the permeate stream, with a high ethanol content, is recycled back to feed the reactors
\end{abstract}

This article has been accepted for publication and undergone full peer review but has not been through the copyediting, typesetting, pagination and proofreading process, which may lead to differences between this version and the Version of Record. Please cite this article as doi: $10.1002 /$ jctb.5186 
CONCLUSION: Incorporating pervaporation modules in the process flowsheet for production of ETBE allows to unload the main separation unit (debutanizer column), thereby reducing energy consumption and operating costs and increasing throughput.

Keywords: Membrane, Pervaporation, Distillation, Simulation, Purification

\section{Introduction}

Public concern against air pollution has boosted research efforts worldwide to improve the quality of motor fuels. The use of oxygenate additives to gasoline that contain oxygen as part of their chemical structure is one of the installed solutions to overcome this atmospheric problem. These additives increment the octane rating and combustion quality and reduce particulate emission and carbon monoxide production. ${ }^{1}$ Alcohol and ethers are common oxygenate compounds. Alcohols, such as methanol and ethanol, are widely used in automobile fuels, whereas tertiary alkyl ethers, such as MTBE and ETBE, are commonly used as octane improvers for liquid fuels, their characteristic low vapor pressure reduces the vapor pressure of gasoline.

As consequence of the negative impacts that MTBE has on the environment, ${ }^{2}$ ETBE has become a popular alternative oxygenate additive for gasoline. In addition, it has higher heating value and lower oxygen content. Considering that the maximum allowed oxygen content in gasoline is $2.7 \%$, the maximum content of ETBE is $17 \mathrm{vol}$. $\%$ and of MTBE is about $15 \%$. Currently, there are no data about ETBE toxicity and adverse environmental impacts. ${ }^{3}$

The etherification reaction of isobutene (IB) with ethanol (EtOH) to produce ethyl tertbutyl ether (ETBE) is carried out industrially as an acid catalyzed liquid phase reaction and is equilibrium-limited. ${ }^{4}$ Isobutene used as reagent is usually part of a mixture with other hydrocarbons of similar boiling points. The hydrocarbon feed composition to an 
etherification unit is essentially fixed by upstream plant operations. Standard FCC units produce $\mathrm{C} 4$ streams with $15-20 \%$ isobutene. The other components are mainly isobutene, 1-butene and n-butane, although other hydrocarbons may also be present. ${ }^{5,6}$ The etherification reaction is highly selective so that nearly only isobutene is converted into ether; an excess of alcohol is usually fed to the reactors in order to achieve high conversions of isobutene.

The reaction is conducted in two sequential reactors to ensure that high conversion is achieved. The reaction proceeds mainly in the first reactor that normally operates isothermally. A tubular reactor is normally used to facilitate the removal of the liberated heat before it affects the reaction equilibrium. ${ }^{6}$ The second stage can be operated adiabatically because of the lower heat generation and thus operation in a packed-bed reactor is more cost-effective. The first reactor operates up to $90{ }^{\circ} \mathrm{C}$, while the second reactor operates in the range $50-60{ }^{\circ} \mathrm{C}$. The product from the second reactor is then purified by distillation in the next stage of the process.

$<$ Figure 1 near here $>$

The ETBE system is susceptible to form azeotropes due to nonidealities in the liquid phase. Azeotropes between ethanol and ETBE and between ethanol and isobutene have been recorded experimentally. ${ }^{7-9}$ In the case of ethanol/ETBE mixtures, these compounds form an azeotropic mixture containing $21.7 \mathrm{wt} \%$ ethanol at 1 bar and 65.6 ${ }^{\circ} \mathrm{C}$. The UNIFAC model predicts the presence of these azeotropes and also suggests an azeotrope between ethanol and 1-butene at high pressure. ${ }^{6,10}$ As consequence of the presence of azeotropes, these mixtures cannot be separated by simple distillation and more advanced alternatives such as pressure-swing distillation ${ }^{10}$ or hybrid processes that combine distillation and pervaporation are required; the latter has been reported to allow cost savings as high as $20 \%{ }^{11,12}$ 
In this study, the optimum design of a hybrid process combining PV with PERVAP 2256 commercial membranes with distillation for ETBE production is proposed based on the comparison of the technical and energy performance of different alternatives. Simulation tasks were carried out with the process simulation software Aspen Plus and the results of alternative process flowsheets that result from the relative location of the separation technologies (for a target product purity) have been compared on the basis of the required membrane area and energy consumption.

\section{Membrane integrated hybrid processes in ETBE production}

Pervaporation is a separation process in which the components from a liquid mixture permeate selectively through a dense membrane driven by a chemical potential gradient favored by reduction of the partial pressure on the permeate side. ${ }^{13}$ The affinity between the permeant and the polymer material that constitutes the membrane, as well as its mobility through the membrane matrix, are the main factors for the transport of the permeating compounds. The permeate side concentration difference is neglected due to the significantly higher diffusion coefficients of the components in the vapor phase compared to the liquid phase. The transport phenomena of pervaporation have been studied and described extensively in the literature. ${ }^{13-15}$ In theory pervaporation can be used to separate any liquid mixtures but in practice, pervaporation tends to be used to separate azeotropic mixture, close boiling-point mixtures, for the recovery of small quantities of impurities and for the enhancement of equilibrium reactions. ${ }^{16-21}$

The separation of organic-organic mixtures is possibly the most challenging application in pervaporation, and for that reason great efforts have been made in the last two decades for the development of new membranes ${ }^{22-27}$ Specifically, for separating alcohol/ether mixtures various membrane materials have been studied, and in recent years some commercial membranes are available. ${ }^{28-32}$ The ability of these membranes to 
break the alcohol/ether azeotropes by means of selective permeation of the alcohol has been experimentally demonstrated.

Despite the advantages, membrane processes often undergo several drawbacks when used alone. Pervaporation alone is unable to achieve products of high purity because it involves working with very low driving force for mass transfer, which results in low permeate fluxes. With the purpose to overcome these constraints, membrane integrated hybrid processes have been developed to optimize the productivity of separation processes. Integrating two unit operations with different separation principles may have a synergetic effect, and the resulting separation may be better than the separation obtained with either unit operation alone. ${ }^{33-36}$

The different types of separation units can be combined in various ways; the pervaporation unit can be positioned i) PV before the distillation column, ii) PV after the column on a side stream or directly in the distillate stream of the column (Fig. 2). Depending on the particular separation task, the configuration and operation of a hybrid system could be designed and optimized using process flow sheet simulation packages to achieve optimal results.

$<$ Figure 2 near here $>$

Several works have been published so far analyzing the performance of hybrid processes for separating MTBE/methanol mixtures as summarized Sridhar et al. ${ }^{37}$ Although the process to produce ETBE is analog, there are remarkable differences in both the characteristics of the mixtures to be separated (i.e. composition of the azeotropes) and in the operating conditions of the equipment (i.e. condenser temperature, pressure in the debutanizer column) that justify the need to analyze this specific case study. 
Lipnizki et al. ${ }^{38}$ reviewed both present and future prospects of pervaporation integrated hybrid processes and analyzed different schemes for several study cases. Streicher et al. ${ }^{39}$ examined an integrated hybrid process combining distillation and PV with alcoholselective membranes. The authors found that this process that combines purification of ETBE and the recycling of the ethanol excess in the bottom product to the reactor is more cost-effective than the conventional two-column distillation process. With similar investment costs the hybrid process could save up to $60 \%$ in operating costs, depending on the plant size and process conditions. Luo et al. ${ }^{40}$ reported research results on the performance of a pervaporation hybrid process for the selective separation of ethanol from ETBE/ethanol mixture. In that work, a cellulose derivative membrane was investigated and the process selectivity and permeability of the components were analyzed. In order to simplify the simulation conditions, Luo et al. ${ }^{40}$ assumed that the feed stream was a binary mixture containing only ethanol and ETBE, and the PV module was connected to the distillate stream. As reported in that paper hybrid processes promise higher economic profits compared to conventional separation processes. However, the approximation of considering a binary mixture might bring errors on the evaluation of the membrane area. Thus, in our study we have considered multicomponent mixtures (including $\mathrm{C} 4$ compounds). In the separation by pervaporation, the mathematical model assumes that only ethanol and ETBE permeate through the membrane, but the presence of $\mathrm{C} 4$ compounds remarkably modifies the activity of the species in the liquid phase, and therefore affects the driving force for pervaporation.

\section{Methodology}

In this paper, three alternative flowsheets of hybrid PV-distillation process for ETBE production are studied (Fig. 2). The objective of this work is to propose a process 
synthesis procedure that allows the determination of the optimal process configuration, design and operation for a given separation target. First, we have carried out a rigorous simulation of the azeotropic distillation column and the pervaporation membrane units with the distillation column parameters previously reported by Streicher et al. ${ }^{10}$ and Alonso $^{41}$. The PV performance is based on the experimental results reported by Ortiz et al. ${ }^{29}$ A mathematical model of the PV membrane modules was developed in Aspen Custom Modeler and integrated with Aspen Plus software. The mass transport rate of the components through the membrane is proportional to the activity gradient of permeant components as driving force. Multicomponent vapor-liquid equilibrium of this mixture has been predicted by using the UNIFAC-Dortmund thermodynamic model. The possibilities of membrane integrated hybrid processes with the design of ReactorPV-Distillation (case A), Reactor-Distillation-PV (with PV on the distillate stream) (case B) and Reactor-Distillation-PV (with PV on a side stream) (case C) alternatives for ETBE production are studied and analyzed (Fig. 2). In addition to the accomplishment of environmental standards, all the studied hybrid processes allow the recovery of over $99 \%$ of ETBE with a purity of at least $95.2 \mathrm{wt} \%$.

In this work the process licensed by Huels ${ }^{42}$ has been chosen for process analysis (Fig 2). In the conventional process, ETBE is recovered as the bottoms product of the distillation unit and the ethanol-rich $\mathrm{C} 4$ distillate is sent to the ethanol recovery section. Water is used to extract the ethanol excess and recycle it back to the process. At the top of the ethanol/water separation column, the ethanol/water azeotrope is recycled to the reactor section; this is a major drawback of the conventional process because water will react with butenes (in the catalytic reactor) to form tertiary butyl alcohol (TBA). ${ }^{43}$ Thus, the use of wet ethanol results in decreased isobutene conversion and ether product purity. Therefore, the use of pervaporation to selectively recover a significant portion of 
the unreacted ethanol will enable us to substantially decrease the amount of water reaching the reaction section and thereby decrease the formation of TBA.

The combination of a pervaporation unit with the distillation column can reduce the complexity and the investment required for a high conversion plant, as well as increase the production of ether by using $\mathrm{C} 4$ streams with higher isobutene content; the hybrid process leads directly to almost pure ether in the bottom stream with the design and operation of the column almost unchanged. In this work the reaction system and debutanizer column used in the conventional process for ETBE production licensed by Huels ${ }^{42}$ has been chosen as the first part of the hybrid process.

\subsection{Thermodynamic method.}

The simulation of the separation section and the optimization of the whole process require the use of thermodynamic models that should predict with precision the vaporliquid equilibria and in particular the presence of azeotropes for the compounds present in the separation section. These include a blend of $\mathrm{C} 4$ hydrocarbons from the feed, ETBE, ethanol and other alcohols from the feed and secondary reactions, and water from secondary reactions as well as from the washing tower used for cleaning the hydrocarbons blend. ${ }^{44}$

As previously reported in literature, ${ }^{45}$ the UNIFAC method is particularly useful for the prediction of the vapor-liquid equilibrium for multicomponent mixtures in the absence of experimental data. In group contribution methods it is assumed that the mixture does not consist of molecules but of functional groups. The required activity coefficients can then be calculated via group activity coefficients when the group interaction parameters between the functional groups are known. In this work we have chosen the UNIFACDortmund group contribution method considering that this thermodynamic method is 
able to predict the non-ideal behavior of the C4/ETBE/ethanol mixtures at moderate pressures. ${ }^{7}$ The Dortmund modified UNIFAC is today the UNIFAC version that has the most extensive parameter table, although some of its parameters are not yet published in the open literature.

\subsection{Modeling the reaction unit}

The synthesis of ETBE is usually performed at medium pressure (10 bar) in liquid phase using an ion exchange resin as catalyst, for example Amberlyst, Lewatit, etc. ${ }^{46,47}$ ETBE is obtained by the reaction between ethanol and isobutylene. The overall scheme of conversion in the synthesis of ETBE can be represented as:

$$
\begin{gathered}
i C_{4}+E t O H \leftrightarrow E T B E \\
i C_{4}+H_{2} O \leftrightarrow T B A \\
2 i C_{4} \rightarrow D I B
\end{gathered}
$$

Etherification reactions are limited by the thermodynamic equilibrium. Etherification and isomerization conversions increase at lower temperature. Although conventional processes typically include two reactors in series, for simulation purposes we have used a single equilibrium reactor as a simplified model which can represent the overall performance of the reaction system. Two parallel reactions, the formation of ETBE and dimerization were considered and for the hydration reaction it was assumed that practically all the water is converted to TBA. ${ }^{41,48}$ Thus, a REquil reactor model (Aspen Plus) with chemical equilibrium constants from literature ${ }^{6,49}$ was used to calculate the products composition and the total molar flow-rate. The REquil reactor does not take into account reaction kinetics, even though the results provide a useful reference to be compared with experimental results, since this equilibrium reactor model can 
adequately describe conversion changes based on the amount of recycled ethanol. The reactor operates at 10 bar and $46{ }^{\circ} \mathrm{C}$, so that water can be used as coolant utility.

\subsection{Modeling of the debutanizer distillation column}

Modeling and simulation of a distillation column for the recovery of $\mathrm{C} 4$ as distillate from C4/ETBE/ethanol mixtures, has been performed using the RadFrac model (Aspen Plus), which describes the full performance of the column through rigorous mathematical methods. The column operation is simulated at constant internal reflux ratio of 0.5 and pressure between 7 bar and 9 bar, with 26 separation stages, including condenser and reboiler.

\subsection{Modeling mass transport in the pervaporation unit}

Modeling and simulation have become indispensable tools for engineers and researchers in synthesis, analysis and optimization of processes. Depending on the requirements of the model, different models with different complexities can be used, which differ greatly in predictive accuracy and determining the appropriate model parameters. ${ }^{14}$

For our study, a global transmembrane model based on the solution-diffusion theory was selected. It assumes equilibrium between the upstream liquid and the upstream membrane surface, and between the downstream vapor and its membrane side. Membrane transport follows Fick's law, with the permeant fugacity difference as the driving force. An intrinsic membrane property is the permeability (permeant flux times membrane thickness divided by permeant driving force) or the permeance (permeant flux divided by the permeant driving force). The latter magnitude is used for asymmetric or composite membranes for which the effective membrane thickness is not readily available..$^{50}$ 
The permeance of component $i$ in the membrane, $Q_{i}$, is defined with regard to the flux $J_{i}$ as:

$$
J_{i}=Q_{i}\left(\hat{f}_{i}^{\text {feed }}-\hat{f}_{i}^{\text {perm }}\right) \approx Q_{i}\left(p_{i}^{o} x_{i}^{\text {feed }} \gamma_{i}-p_{i}^{\text {perm }}\right)
$$

where $\hat{f}_{i}^{\text {feed }}$ and $\hat{f}_{i}^{\text {perm }}$ are the fugacities of component $i$ in the feed mixture and in the permeate side of the membrane, respectively. The saturation vapor pressure $\left(p_{i}^{o}\right)$ is obtained from the Antoine equation and the activity coefficients $\left({ }^{\gamma_{i}}\right)$ have been obtained using the UNIFAC-Dortmund model.

The activities of the components in the liquid phase are calculated as:

$$
a_{i}=x_{i} \gamma_{i}
$$

In this work we have used the experimental data for the separation of ETBE/ethanol mixtures by pervaporation with PERVAP 2256 commercial membranes reported in previous papers by our research group. Those experimental data have now been incorporated into a model that describes the mass transport through the membrane as a function of the activity of the components and operating conditions. As reported by Ortiz et al., ${ }^{29}$ the partial fluxes are a nonlinear function of the activity of the components, which means that the permeances are not constant but depend on the activity of the components. Therefore, taking into account the various semi-empirical models reported in literature, we have adjusted the ethanol permeability data to an equation that depends only on the activity of ethanol, as follows:

$$
Q_{\text {ethanol }}=A_{1}+B_{1} *\left(a_{\text {ethanol }}\right)^{C_{1}}
$$

With regard to ETBE, we have found that its permeance can be described as a function of the activities of both ethanol and ETBE, as follows:

$$
Q_{E T B E}=A_{2}+B_{2} *\left(a_{\text {ETBE }}\right)+C_{2} *\left(a_{\text {ethanol }}\right)
$$


We have assumed that only two components (ethanol and ETBE) permeate through the membrane, while the rest of the components remain at the retentate side and do not permeate. This simplification was experimentally tested with the membrane PERVAP 2256 used to find the experimental data.

In this study, the temperature dependence of membrane permeance in the proposed mathematical model was described trough the Arrhenius-type equation (Eq. 8),

$Q_{i, T}=Q_{i, T o} \exp \left(\frac{-E_{a c t, i}}{R T}\right)$

Experimental permeation data from Alonso ${ }^{41}$ have been fitted to Eqs. (6-8) using the Aspen Custom Modeler (AspenTech) software tool, obtaining the estimated parameters that are reported in Table 1 . The experimental data used to estimate the model parameters were obtained from laboratory-scale experiments performed under isothermal conditions.

$<$ Table 1 near here $>$

In order to simulate the behavior of a pervaporation module at industrial scale, a mathematical model of a plate and frame membrane module was adapted from Luyben ${ }^{51}$ where the above membrane performance model was incorporated. Steady state mass and energy balances were developed considering (i) plug-flow for the feed liquid stream, (ii) perfect mixing in the permeated vapor, (iii) negligible pressure drop within the module, (iv) negligible polarization effects and (v) negligible heat losses. For calculation purposes a discretization technique has been applied: the membrane module has been divided into a set of cells; five cells have been considered in each membrane module. The dynamic changes in composition and temperature of the retentate in each cell are described by means of ordinary differential equations. As heat resistances through the membrane are usually negligible, the temperature on the retentate and permeate sides in 
each cell are assumed to be equal. The molar holdup in each cell $M_{R}$ is assumed constant, so the total molar balance is algebraic. Thus the mass and energy balances are as follows:

$$
\begin{aligned}
& \frac{d M_{R}}{d t}=0=F_{R, n-1}-F_{R, n}-F_{P, n} \\
& M_{R} \frac{d h_{R, n}}{d t}=0=F_{R, n-1} h_{R, n-1}-F_{R, n} h_{R, n}-F_{P, n} H_{P, n} \\
& M_{R} \frac{d z_{R, n, i}}{d t}=0=F_{R, n-1} z_{R, n-1, i}-F_{R, n} z_{R, n, i}-F_{P, n} Z_{P, n, i}
\end{aligned}
$$

where

$F_{R, n}=$ molar flowrate of the liquid retentate from cell $n\left(\mathrm{kmol} \mathrm{h}^{-1}\right)$

$F_{P, n}=$ molar flowrate of vapor permeate from cell $n\left(\mathrm{kmol} \mathrm{h}^{-1}\right)$

$h_{R, n}=$ molar enthalpy of liquid retentate in cell $n\left(\mathrm{GJ} \mathrm{kmol}^{-1}\right)$

$H_{P, n}=$ molar enthalpy of vapor permeate leaving cell $n\left(\mathrm{GJ} \mathrm{kmol}^{-1}\right)$

$Z_{R, n, i}=$ mole fraction of component $i$ in the liquid retentate in cell $n$.

$Z_{P, n, i}=$ mole fraction of component $i$ in the vapor permeate leaving cell $n$.

The permeate flowrate is the sum of the two components (ethanol and ETBE) fluxes times the membrane area $\left(A_{\text {mem }}\right)$ as given by Eq. 12, and the composition of the permeate is given by the ratio of partial to total flux (Eq. 13).

$$
\begin{aligned}
& F_{P, n}=A_{\text {mem }}\left(J_{n, \text { ethanol }}+J_{n, E T B E}\right) \\
& Z_{P, n, i}=A_{\text {mem }} \times \frac{J_{n, i}}{F_{P, n}}
\end{aligned}
$$

The flux of component " $i$ " in each cell is calculated using the following equation:

$$
J_{i}=Q_{i}\left(z_{R i} \gamma_{i} P_{i}^{s a t}-z_{P i} P_{\text {permeate }}\right)
$$

The temperature of the retentate is calculated from the known liquid enthalpy $h_{R, n}$ and the known retentate composition $Z_{R, n}$ using physical properties relationships. 
The Aspen Custom Modeler (ACM) software is used to simulate the pervaporation process. Composition and temperature of the retentate and permeate streams are variables distributed along the module, which are computed by simultaneously solving the material and energy balances (Eqs. 9-11). To do this, the thermodynamic properties that are a function of temperature and composition need to be computed in each cell using subroutines specific in ACM software. Thus, properties such as activity coefficients, vapor pressure, density, heat capacity, and liquid and vapor enthalpies are calculated as variables distributed along the membrane module. In addition, the membrane permeances are also calculated in each cell using the equations of the proposed model (Eqs. 6-8) as a function of the activities and temperature. The differential and algebraic equations (Eqs. 6-14) for each cell and each module are incorporated in the Aspen Custom Modeler program. The ACM model is then exported to Aspen Plus software as a standalone module to integrate the pervaporation membrane module into global flowsheets. So we can evaluate diagrams with different configurations or different number of membrane modules, and analyze the influence of the recycling streams (recovered unreacted ethanol). Considering the commercially available pervaporation modules, a membrane area of $30 \mathrm{~m}^{2}$ for each module was assumed. Permeating molecules are removed from the downstream surface of the membrane in the vapor phase, and the latent heat for the phase change is obtained from the sensible heat of the feed. ${ }^{52}$ Thus, in PV cells a temperature drop will be observed between the feed inlet and the retentate outlet streams. Feed pressure has been chosen such that the feed to the PV modules is in the liquid state at the operating temperature $\left(70{ }^{\circ} \mathrm{C}\right)$. 


\section{Results and discussion}

We have adopted as reference process the one in operation at "Petróleos del Norte SA" (a petrochemical Spanish company) which employs a $\mathrm{C} 4$ hydrocarbon stream as feedstock, with $19 \%$ molar content of isobutene as well as the provision of ethanol in excess $(\sim 10 \%)$, as it has been reported by García-Echevarría. ${ }^{53}$

The methodology presented above is applied to the separation of ethanol from ethanol/ETBE/C4 mixtures in order to achieve a productivity of $6400 \mathrm{~kg} \mathrm{~h}^{-1}$ of ETBE with a minimum purity of $95.2 \mathrm{wt} \%$. It is assumed that all C4-C6 hydrocarbons except isobutene are inert. ${ }^{6}$ Therefore, all the inert $\mathrm{C} 4$ hydrocarbons are lumped, based on their similarities, and represented here by n-butene.

The feed stream to the membrane modules is considered to be in liquid phase. The values adopted in this work were $70{ }^{\circ} \mathrm{C}$ for the feed temperature and $20 \mathrm{mmHg}(2.7$ $\mathrm{kPa}$ ) for the permeate pressure. Feed pressure is chosen such that the feed to the pervaporation module is in liquid phase at the operating temperature and varies between 4.8 and 7.5 bar depending on the $\mathrm{C} 4$ content of the liquid mixture to be separated.

Simulation runs of the hybrid process have been performed in order to understand the impact of different process configurations and parameters, and the results have been compared on the basis of the required membrane area as shown in Fig. 3. The purity of ETBE reported in Fig. 3 refers to the ETBE content in the product stream which in the 3 cases is obtained as a bottom stream in the debutanizer column.

The pervaporation unit can be placed directly after the reactor outlet (case A, Fig. 2a) to remove the unreacted ethanol. Other option is to place the pervaporation unit after the distillate stream of distillation column (Case B, Fig. 2b). A third alternative configuration takes a side withdrawal from the debutanizer column to the pervaporation unit to remove ethanol (Case C, Fig. 2c). All alternatives can be used for ETBE 
production. The only difference between them is the energy consumption, required membrane area and ethanol content in the distillate stream. In the " $\mathrm{C}$ " alternative, the chosen stage of extraction is the one where a peak in the concentration profile of ethanol in the liquid phase is noticed, as discussed below. Another option would be processing the bottom stream by means of pervaporation, but this option will be hardly competitive from an economic point of view, since the final product specification would require an enormous membrane area due to the low driving force. ${ }^{12,54}$

$<$ Figure 3 near here $>$

Option A: pervaporation followed by distillation

The dependence of the ETBE quality upon the membrane area needed in each case is plotted in Fig. 3. The target ETBE purity will depend on its final use; in this paper we have considered that a content of at least $95.2 \mathrm{wt} \%$ ETBE is required to be used as an additive for gasoline. Fig. 3 shows that the required membrane area to obtain $6393 \mathrm{~kg} \mathrm{~h}^{-}$ ${ }^{1}$ of product is about $660 \mathrm{~m}^{2}$. The feed flow rate to the membrane system is very high and it has to be argued whether this possibility would be really feasible. ${ }^{54}$ With regard to the trend observed in case A, the stream to be processed by PV (from the reaction zone) contains $2.6 \mathrm{wt} \%$ ethanol and at the outlet of the last membrane module contains 2.2 $\mathrm{wt} \%$ ethanol (retentate stream). This makes the driving force for separation much smaller compared to case $\mathrm{C}$ and consequently the required area is larger. As the processed stream is depleted in ethanol the required area is increasing, resulting in the slope change observed in Fig. 3. A similar behavior has been previously reported in the literature for the analogous case of MTBE production. ${ }^{12,53}$

Option B: pervaporation on the distillate stream

This case, although technically feasible, involves processing a stream that is more difficult to handle due to its high content of $\mathrm{C} 4$ components. Therefore pervaporation 
modules should work at pressures higher than 8 bar on the liquid side to avoid partial vaporization of the feed mixture. Fig. 3 shows that the required membrane area for case $B$ is about $240 \mathrm{~m}^{2}$. In case $\mathrm{B}$, the required membrane area is lower than in the previous alternative, but the ethanol content in the $\mathrm{C} 4$ outlet stream is higher. This motivated us to seek other alternative (option C) in which a higher amount of ethanol separated by PV can be recycled to the reaction zone.

The internal profiles for the main components in the debutanizer column corresponding to cases A and B are plotted in Figures 4 and 5. A clear difference between the two figures can be observed with respect to the ethanol peak in the rectification section: in case A the ethanol peak is lower because the column is fed with a stream that has been partially depleted in ethanol by pervaporation.

$<$ Figures 4 and 5 near here $>$

Option C: pervaporation parallel to the distillation column

This configuration is possible because ethanol accumulates in the debutanizer column, due to the VLE behavior of the system. In the process studied in Case C, pressure and temperature of the stream fed to the column have to be optimized. Therefore, a study has been made to establish the thermal condition that leads to a higher ethanol concentration in the liquid phase inside the column. Simulations have been run for the standalone distillation column (decoupled from pervaporation) to be used as reference and to study its behavior when the feed mixture is fed to the column as saturated liquid or partially vaporized mixture, with the design and operation parameters of the column remaining unchanged. Simulated data indicate that higher ethanol concentration in the liquid phase is obtained when feeding a saturated liquid (Fig. 6).

$<$ Figure 6 near here $>$

This article is protected by copyright. All rights reserved. 
In Fig. 7 the liquid concentration and temperature profiles inside the column (coupled to PV) are shown. The existence of a maximum content of EtOH in the liquid phase can be observed around stage $18(27 \mathrm{wt} \% \mathrm{EtOH})$, together with a very low content of $\mathrm{C} 4$ hydrocarbons. The distillation column has 26 stages, and we have found that for the case "C" the most suitable work conditions are as follows: the fresh feed is located in stage 11 , the liquid side withdrawal in stage 18 , and the permeate from the membrane modules is recycled in stage 23. Thus, 7 PV modules are required to obtain the specified composition of ETBE in the bottom stream. In these conditions about $6420 \mathrm{~kg} \mathrm{~h}^{-1}$ of ETBE with a purity of $95.2 \mathrm{wt} \%$ is obtained, this implies that $99.9 \%$ of the produced ETBE leaving the reactor is recovered in the bottom of the column.

$<$ Figure 7 near here $>$

In the search for the optimal operating conditions, we have also evaluated the influence of the sidestream flow rate on the separation performance. As shown in Fig. 8 for a hybrid process including $7 \mathrm{PV}$ modules, mass flow rates higher than $1200 \mathrm{~kg} \mathrm{~h}^{-1}$ are required to achieve the product specification (95.2 wt\% ETBE). We have found that a mass flow rate of $1260 \mathrm{~kg} \mathrm{~h}^{-1}$ is the most appropriate to achieve the required purity of ETBE, while the content of ethanol and butenes is at a minimum value. A further increase in the sidestream flow rate does not result in an improved separation.

$<$ Figure 8 near here $>$

It is well known the important influence of temperature on the driving force for pervaporation process, and therefore on the membrane performance. Therefore it is advisable to operate the PV process at the highest possible temperature. The practical limit of operating temperature $\left(80^{\circ} \mathrm{C}\right.$, according to the technical data sheet $)$ is determined by the thermal stability of the membrane. However, in this case we have adopted a feed temperature of $70{ }^{\circ} \mathrm{C}$ in order to avoid working at too high pressures. 
Pervaporation operates in adiabatic mode, so the process requires the feed liquid to be repeatedly reheated to supply the latent heat of evaporation removed by the permeating vapor. ${ }^{52}$ The need for interstage reheating complicates the system design and leads to lower average fluxes (as opposed to a hypothetical isothermal process). In our case, since we have selected membrane modules with $30 \mathrm{~m}^{2}$ of area, the temperature drop in the liquid in the direction of flow is a free parameter that depends on the depletion of the ethanol concentration contained in the mixture being processed. Thus, in the case $\mathrm{C}$ the feed stream must be reheated six times as the ethanol concentration drops from 27 to $19 \%$ and the average temperature of the fluid is at about $65{ }^{\circ} \mathrm{C}$. Figure 9 shows the temperature profile of the retentate stream with heating between every PV module. The retentate streams leaving each module are heated back up to $70{ }^{\circ} \mathrm{C}$. A temperature drop in a module of $3-10{ }^{\circ} \mathrm{C}$ is generally assumed in the design and operation of commercial pervaporation units. ${ }^{55}$ As can be seen in Fig. 9, the temperature drop per module is within the suggested range. The drop in the retentate temperature in the last modules is quite small because the flux rates are small too owing to the decrease in the retentate ethanol composition.

$<$ Figure 9 near here $>$

On the other hand, it has been verified experimentally ${ }^{28,41}$ that the influence of the permeate pressure on the mass transport rate can be neglected in the range $1-20 \mathrm{mmHg}$, and the choice of the highest value will allow the costs of permeate condensation to be reduced without leading to an increase in the membrane area needed.

In case $A$, case $B$ and case $C$ the required membrane area is $660 \mathrm{~m}^{2}, 240 \mathrm{~m}^{2}$ and $210 \mathrm{~m}^{2}$, respectively. ETBE content in the distillate stream is negligible in all cases. In case B, the EtOH content in the distillate stream and the utility energy consumption are higher than in case $\mathrm{C}$, although similar areas are required in both hybrid processes. As 
mentioned above the target purity of ETBE is $95.2 \mathrm{wt} \%$ for all of the process alternatives. The final design data for the hybrid process are summarized in Table 2.

$<$ Table 2 near here $>$

$<$ Table 3 near here $>$

As shown in Table 3, consumption of utilities (low and medium pressure steam, refrigerant, and cooling water) differs for each case depending on the column reboiler and condenser duty as well as the number of pervaporation units, because each unit needs of a separate heat exchanger. Table 3 gives detailed information about the expected utility usage in the different alternatives. The amount of refrigerant and electricity consumed is not significant in relation to the total energy consumption. Differences between the amounts of energy consumed by the hybrid processes mainly depend on the combination of distillation column and pervaporation, as well as on the number of modules of pervaporation. A scheme of the final hybrid process for cases A, $\mathrm{B}$ and $\mathrm{C}$ is displayed in Figures 10, 11 and 12, respectively.

$<$ Figures 10,11 and 12 near here $>$

\section{Conclusions}

This work reports the comparative analysis of hybrid process alternatives based on the combination of distillation and pervaporation operations for the production of ETBE. We propose the use of pervaporation to unload a distillation column, thereby reducing energy consumption and operating costs and increasing throughput. Mathematical modeling and simulation of the membrane module have been performed using Aspen Custom Modeler and linked with Aspen Plus software to describe the overall process. Three different options that resulted from the relative location of the separation technologies were considered. The final configuration with the lower energy consumption and ethanol impurity in the distillate stream was determined. 
Through comparisons of various hybrid processes, we found that the hybrid process designed in case $\mathrm{C}$, in which the pervaporation modules are located on a side-stream withdrawn from the distillation column, is more favorable in energy consumption and it shows lower content of ethanol in distillate stream than other membrane integrated hybrid processes. Thus, in the case of study analyzed 7 PV modules, with a total membrane area of $210 \mathrm{~m}^{2}$, are required to obtain $6420 \mathrm{~kg} \mathrm{~h}^{-1}$ de ETBE with a purity of $95.2 \mathrm{wt} \%$. At the same time, by recycling the permeate rich in ethanol to the reaction area, allows us to slightly increase the conversion of isobutene to 0.943 .

\section{Acknowledgements}

Financial support from the Spanish Ministry of Science under the projects CTM201344081-R (MINECO, Spain-FEDER 2014-2020), CTQ2015-66078-R and CTQ201675158-R is gratefully acknowledged. Adham Norkobilov also thanks the SILKROUTE Project for a PhD scholarship funded by the European Commission through the Erasmus Mundus Action 2 Programme.

\section{References}

1. Yee KF, Mohamed AR, Tan SH, A review on the evolution of ethyl tert-butyl ether (ETBE) and its future prospects. Ren Sust Energ Rev 22:604-20 (2013).

2. Donahue CJ, D'Amico T, Exline JA, Synthesis and characterization of a gasoline oxygenate, ethyl tert-butyl ether. J Chem Educ 79:724-6 (2002).

3. Fayolle-Guichard F, Durand J, Cheucle M, Rosell M, Michelland RJ, Tracol J, Le Roux F, Grundman G, Atteia O, Richnow HH, Dumestre A, Benoit Y, Study of an aquifer contaminated by ethyl tert-butyl ether (ETBE): Site characterization and on-site bioremediation. J Hazard Mater 201-202:236-43 (2012). 
4. Ryll O, Blagov S, Hasse H, Thermodynamic analysis of reaction-distillation processes based on piecewise linear models. Chem Eng Sci 109:284-95 (2014).

5. Miracca I, Tagliabue L, Trotta R, Multitubular reactors for etherifications. Chem Eng Sci 51:2349-58 (1996).

6. Sneesby MG, Tadé MO, Datta R, Smith TN, ETBE synthesis via reactive distillation. 1. steady-state simulation and design aspects. Ind Eng Chem Res 36:1855-69 (1997).

7. Gmehling J, Menke J, Krafczyk J, Fischer K, A data bank for azeotropic data - status and applications. Fluid Phase Equilib 103:51-76 (1995).

8. Fischer K, Park S, Gmehling J, Vapor-liquid equilibria for binary systems containing methanol or ethanol, tert-butyl methyl ether or tert-amyl methyl ether, and butane or 2methylpropene at 363 K. ELDATA Int Electron J Phys -Chem Data 2:135-48 (1996). 9. Oh JH, Park SJ, Isothermal vapor-liquid equilibria for binary and ternary systems containing ethyl tert-butyl ether, ethanol, benzene, and toluene at 313.15 K. J Ind Eng Chem 11:456-64 (2005).

10. Streicher C, Asselineau L, Forestière A, Separation of alcohol/ether/hydrocarbon mixtures in industrial etherification processes for gasoline production. Pure Appl Chem 67:985-92 (1995).

11. Chen MS, Eng RM, Glazer JL, Wensley CG, inventors; Pervaporation process for separationg alcohols from ethers. US Patent 4,774,365 (1988).

12. González B, Ortiz I, Modelling and simulation of a hybrid process (pervaporationdistillation) for the separation of azeotropic mixtures of alcohol-ether. J Chem Technol Biotechnol 77:29-42 (2002).

13. Néel J, Pervaporation. Tech\&Doc/Lavoisier, Paris (1997).

14. Lipnizki F, Trägårdh G, Modelling of pervaporation: Models to analyze and predict the mass transport in pervaporation. Sep Purif Methods 30:49-125 (2001). 
15. Luis $\mathrm{P}$, Van der Bruggen B, Pervaporation modeling: State of the art and future trends, in Pervaporation, Vapour Permeation and Membrane Distillation, ed by Basile A, Figoli A, Khayet M., Woodhead Publishing, Oxford (2015). 16. Vane LM, A review of pervaporation for product recovery from biomass fermentation processes. J Chem Technol Biotechnol 80:603-29 (2005). 17. Ortiz I, Gorri D, Casado C, Urtiaga A, Modelling of the pervaporative flux through hydrophilic membranes. J Chem Technol Biotechnol 80:397-405 (2005).

18. Chapman PD, Oliveira T, Livingston AG, Li K, Membranes for the dehydration of solvents by pervaporation. J Membr Sci 318:5-37 (2008).

19. García V, Diban N, Gorri D, Keiski R, Urtiaga A, Ortiz I, Separation and concentration of bilberry impact aroma compound from dilute model solution by pervaporation. J Chem Technol Biotechnol 83:973-82 (2008).

20. Van der Bruggen B, Luis P, Pervaporation as a tool in chemical engineering: A new era? Curr Opin Chem Eng 4:47-53 (2014).

21. Orozco-González N, Bustamante F, Acosta-Cárdenas A, Experimental assessment of the integration of in situ removal of ethanol by pervaporation with a simultaneous saccharification-fermentation process. J Chem Technol Biotechnol 91:3011-7 (2016). 22. Doghieri F, Nardella A, Sarti GC, Valentini C, Pervaporation of methanol-MTBE mixtures through modified poly(phenylene oxide) membranes. J Membr Sci 91:283-91 (1994).

23. Smitha B, Suhanya D, Sridhar S, Ramakrishna M, Separation of organic-organic mixtures by pervaporation - A review. J Membr Sci 241:1-21 (2004).

24. Villaluenga JPG, Godino P, Khayet M, Seoane B, Mengual JI, Pervaporation of alcohols and methyl tert-butyl ether through a dense poly(2,6-dimethyl-1,4-phenylene oxide) membrane. Ind Eng Chem Res 43:2548-55 (2004). 
25. Zereshki S, Figoli A, Madaeni SS, Galiano F, Drioli E, Pervaporation separation of ethanol/ETBE mixture using poly(lactic acid)/poly(vinyl pyrrolidone) blend membranes. J Membr Sci 373:29-35 (2011).

26. Wang M, Arnal-Herault C, Rousseau C, Palenzuela A, Babin J, David L, Jonquieres A, Grafting of multi-block copolymers: A new strategy for improving membrane separation performance for ethyl tert-butyl (ETBE) bio-fuel purification by pervaporation. J Membr Sci 469:31-42 (2014).

27. Villegas M, Romero AI, Parentis M, Castro Vidaurre EF, Gottifredi JC, Acrylic acid plasma polymerized poly(3-hydroxybutyrate) membranes for methanol/MTBE separation by pervaporation. Chem Eng Res Des 109:234-48 (2016).

28. González B, Ortiz I, Mathematical modeling of the pervaporative separation of methanol-methylterbutyl ether mixtures. Ind Eng Chem Res 40:1720-31 (2001). 29. Ortiz I, Alonso P, Urtiaga A, Pervaporation of azeotropic mixtures ethanol/ethyl tert-butyl ether: Influence of membrane conditioning and operation variables on pervaporation flux. Desalination 149:67-72 (2002).

30. Gorri D, Ibáñez R, Ortiz I, Comparative study of the separation of methanol-methyl acetate mixtures by pervaporation and vapor permeation using a commercial membrane. J Membr Sci 280:582-93 (2006).

31. Matuschewski H, Schedler U, MSE - modified membranes in organophilic pervaporation for aromatics/aliphatics separation. Desalination 224:124-31 (2008).

32. Genduso G, Luis P, Van der Bruggen B, Overcoming any configuration limitation: An alternative operating mode for pervaporation and vapour permeation. $J$ Chem Technol Biotechnol 91:948-57 (2016).

33. Koczka K, Mizsey P, Fonyo Z, Rigorous modelling and optimization of hybrid separation processes based on pervaporation. Cent Eur J Chem 5:1124-47 (2007). 
34. Vane LM, Alvarez FR, Membrane-assisted vapor stripping: Energy efficient hybrid distillation - vapor permeation process for alcohol - water separation. J Chem Technol Biotechnol 83:1275-87 (2008).

35. Luis P, Amelio A, Vreysen S, Calabro V, Van der Bruggen B, Simulation and environmental evaluation of process design: Distillation vs. hybrid distillationpervaporation for methanol/tetrahydrofuran separation. Appl Energy 113:565-75 (2014). 36. Kiss AA, Distillation technology - still young and full of breakthrough opportunities. J Chem Technol Biotechnol 89:479-98 (2014).

37. Sridhar S, Smitha B, Shaik A, Pervaporation-based separation of methanol/MTBE mixtures - A review. Sep Purif Rev 34:1-33 (2005).

38. Lipnizki F, Field RW, Ten PK, Pervaporation-based hybrid process: A review of process design, applications and economics. J Membr Sci 153:183-210 (1999).

39. Streicher C, Kremer P, Tomas V, Hubner A, Ellinghorst G, Development of new pervaporation membranes, systems and processes to separate alcohols/ethers/hydrocarbons mixtures, in Proc. 7th Int. Conf. Pervaporation Processes in the Chemical Industry, ed. Bakish, R., Bakish Materials Corp., Englewood, pp. 297309 (1995).

40. Luo GS, Niang M, Schaetzel P, Separation of ethyl tert-butyl ether-ethanol by combined pervaporation and distillation. Chem Eng J 68:139-43 (1997).

41. Alonso-Dávila P, Diseño de un proceso óptimo para la producción de éter etil tertbutílico. PhD dissertation, Universidad de Cantabria (2003).

42. Obenaus F, Droste W, Hüls-process: Methyl tertiary butylether. Erdol \& Kohle Erdgas Petrochem 33:271-5 (1980). 
43. Cunill F, Vila M, Izquierdo JF, Iborra M, Tejero J, Effect of water presence on methyl tert-butyl ether and ethyl tert-butyl ether liquid-phase syntheses. Ind Eng Chem Res 32:564-9 (1993).

44. Verrazzi A, Kikic I, Garbers P, Barreau A, Le Roux D, Vapor-liquid equilibrium in binary systems ethanol $+\mathrm{C}_{4}$ and $\mathrm{C}_{5}$ hydrocarbons. J Chem Eng Data 43:949-53 (1998). 45. Gmehling J, Constantinescu D, Schmid B, Group contribution methods for phase equilibrium calculations. Annu Rev Chem Biomol Eng 6:267-92 (2015).

46. Fité C, Iborra M, Tejero J, Izquierdo JF, Cunill F, Kinetics of the liquid-phase synthesis of ethyl tert-butyl ether (ETBE). Ind Eng Chem Res 33:581-91 (1994). 47. Zhang T, Jensen K, Kitchaiya P, Phillips C, Datta R, Liquid-phase synthesis of ethanol-derived mixed tertiary alkyl ethyl ethers in an isothermal integral packed-bed reactor. Ind Eng Chem Res 36:4586-94 (1997).

48. Quitain A, Itoh H, Goto S, Reactive distillation for synthesizing ethyl tert-butyl ether from bioethanol. J Chem Eng Jpn 32:280-7 (1999).

49. Izquierdo JF, Cunill F, Vila M, Iborra M, Tejero J, Equilibrium constants for methyl tert-butyl ether and ethyl tert-butyl ether liquid-phase syntheses using C4 olefinic cut. Ind Eng Chem Res 33:2830-5 (1994).

50. Wijmans JG, Process performance $=$ membrane properties + operating conditions. $J$ Membr Sci 220:1-3 (2003).

51. Luyben WL, Control of a column/pervaporation process for separating the ethanol/water azeotrope. Ind Eng Chem Res 48:3484-95 (2009).

52. Baker RW, Membrane technology and applications. $3^{\text {rd }}$ ed., John Wiley \& Sons, Chichester (2012).

53. García-Echevarría M, La producción de biocarburantes por Petronor contribuye al uso de energías renovables. DYNA 78:26-30 (2003). 
54. Hömmerich U, Rautenbach R, Design and optimization of combined pervaporation/distillation processes for the production of MTBE. J Membr Sci 146:5364 (1998).

55. Dutta BK, Ji W, Sikdar SK, Pervaporation: Principles and applications. Sep Purif Methods 25:131-224 (1996). 


\section{List of captions}

Figure 1. Schematic flow diagram of the conventional Huels process for ETBE production.

Figure 2. PV integrated design alternatives for the purification of product streams in the ETBE production.

Figure 3. Dependence of ETBE product quality on membrane area for different alternatives of hybrid process

Figure 4. Concentration of main components and temperature profile in the debutanizer column (Case A).

Figure 5. Concentration of main components and temperature profile in the debutanizer column (Case B).

Figure 6. Ethanol concentration profile (liquid) in the debutanizer column for varying feed conditions

Figure 7. Liquid mass fraction of components and temperature profile in the debutanizer column (Case C).

Figure 8. Effect of the sidestream flow rate on bottom product composition.

Figure 9. Temperature profile of the retentate stream with heating between every PV module.

Figure 10. Schematic diagram of optimized hybrid process for Case A.

Figure 11. Schematic diagram of optimized hybrid process for Case B.

Figure 12. Schematic diagram of optimized hybrid process for Case C.

Figure 1. Schematic flow diagram of the conventional Huels process for ETBE production

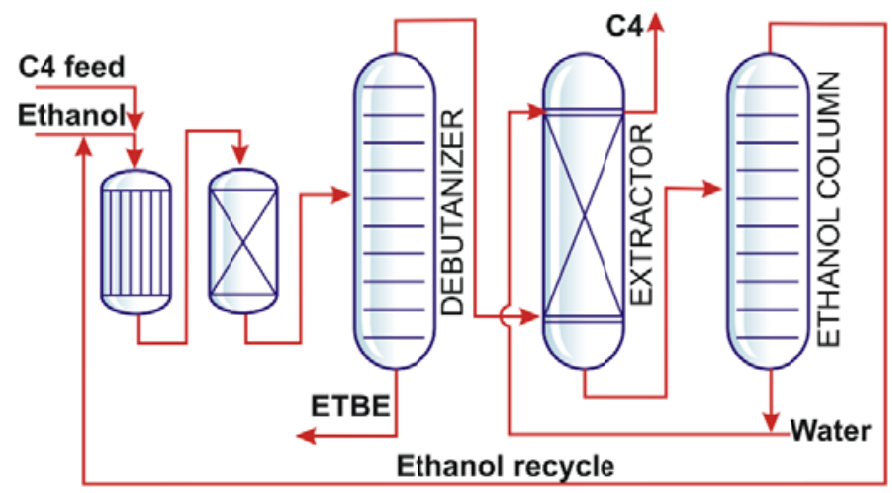

This article is protected by copyright. All rights reserved. 
Figure 2. PV integrated design alternatives for the purification of product streams in the ETBE production

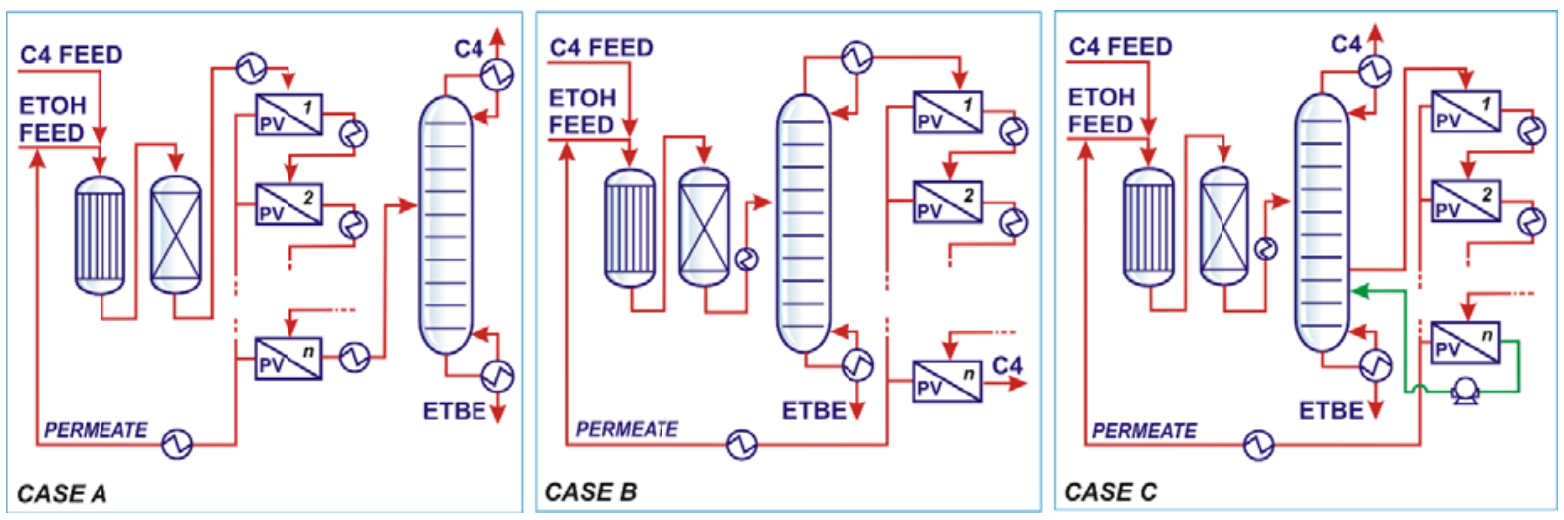

Figure 3. Dependence of ETBE product quality on membrane area for different alternatives of hybrid process

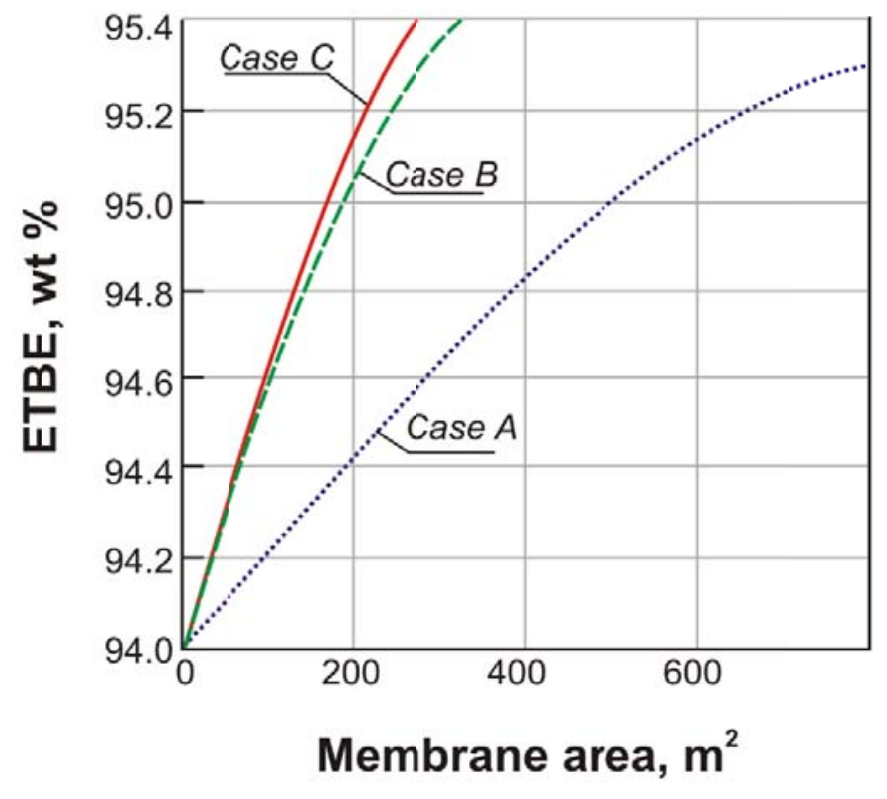

This article is protected by copyright. All rights reserved. 
Figure 6. Ethanol concentration profile (liquid) in the debutanizer column for varying feed conditions

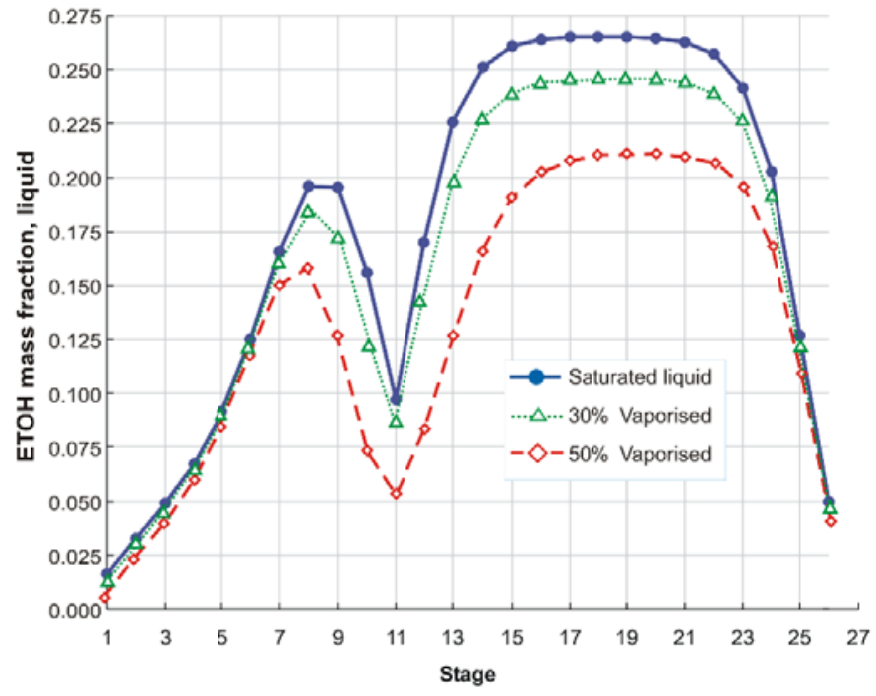

Figure 7. Liquid mass fraction of components and temperature profile in the debutanizer column (Case C).

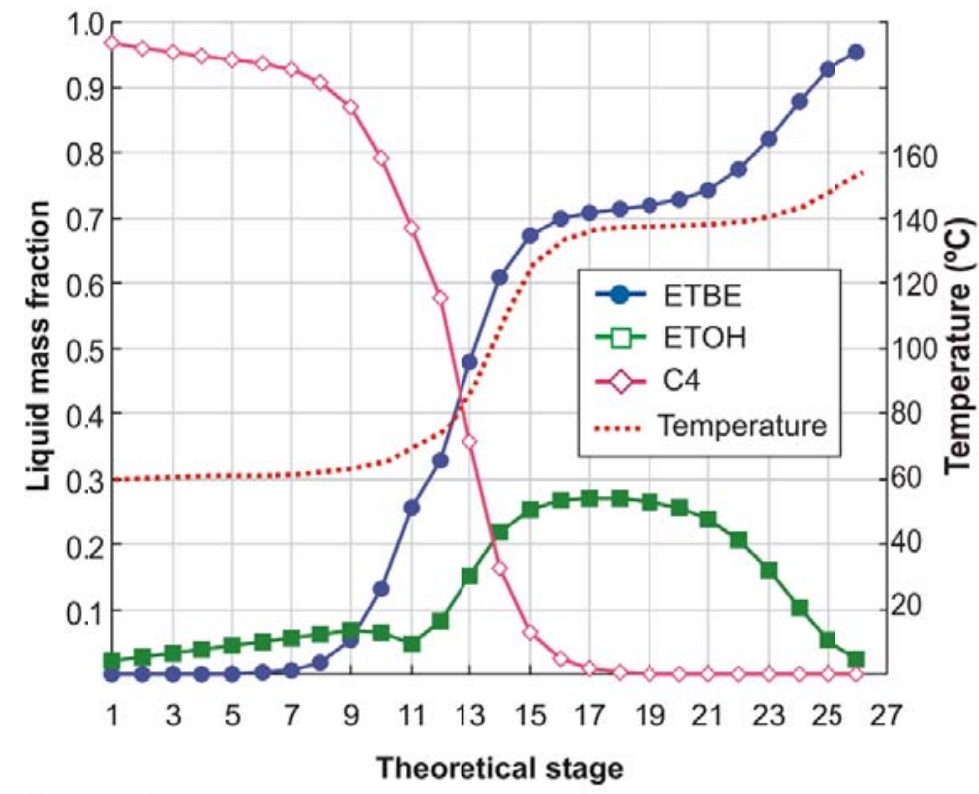

Case $C$ 
Figure 8. Effect of the sidestream flow rate on bottom product composition.

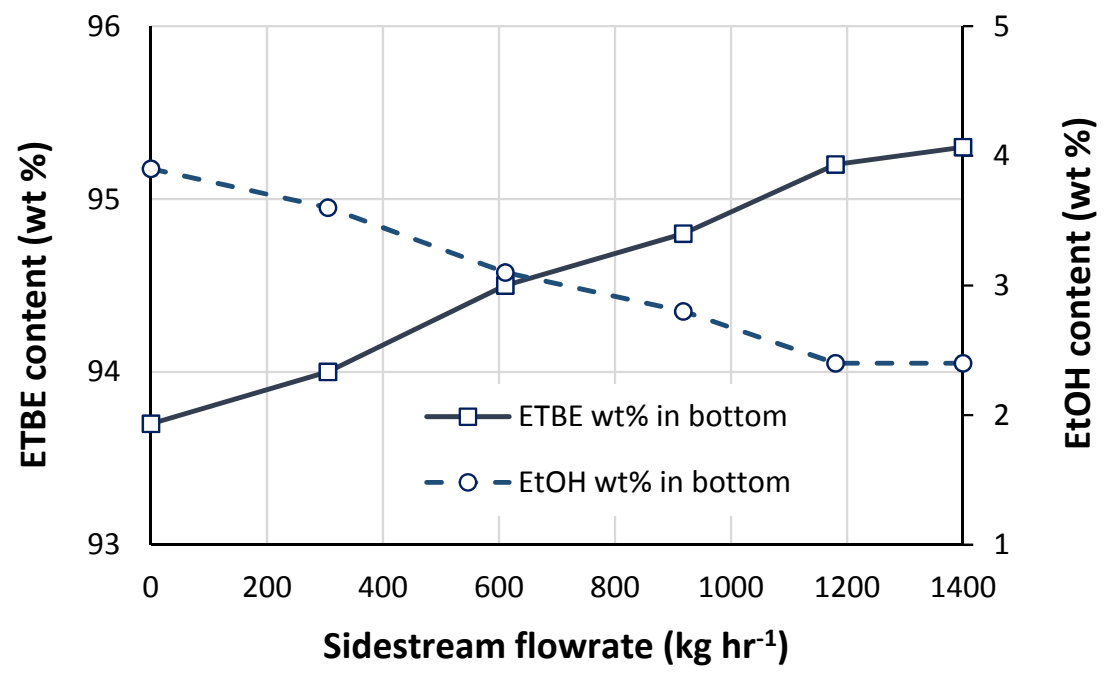

Figure 9. Temperature profile of the retentate stream with heating between every PV module.

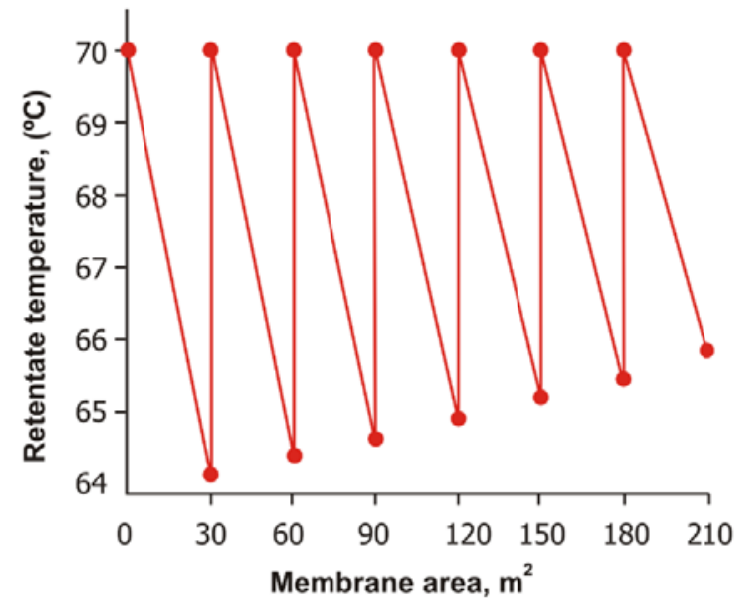

This article is protected by copyright. All rights reserved. 
Figure 12. Schematic diagram of optimized hybrid process for Case C (Compositions are given as $w t \%)$.

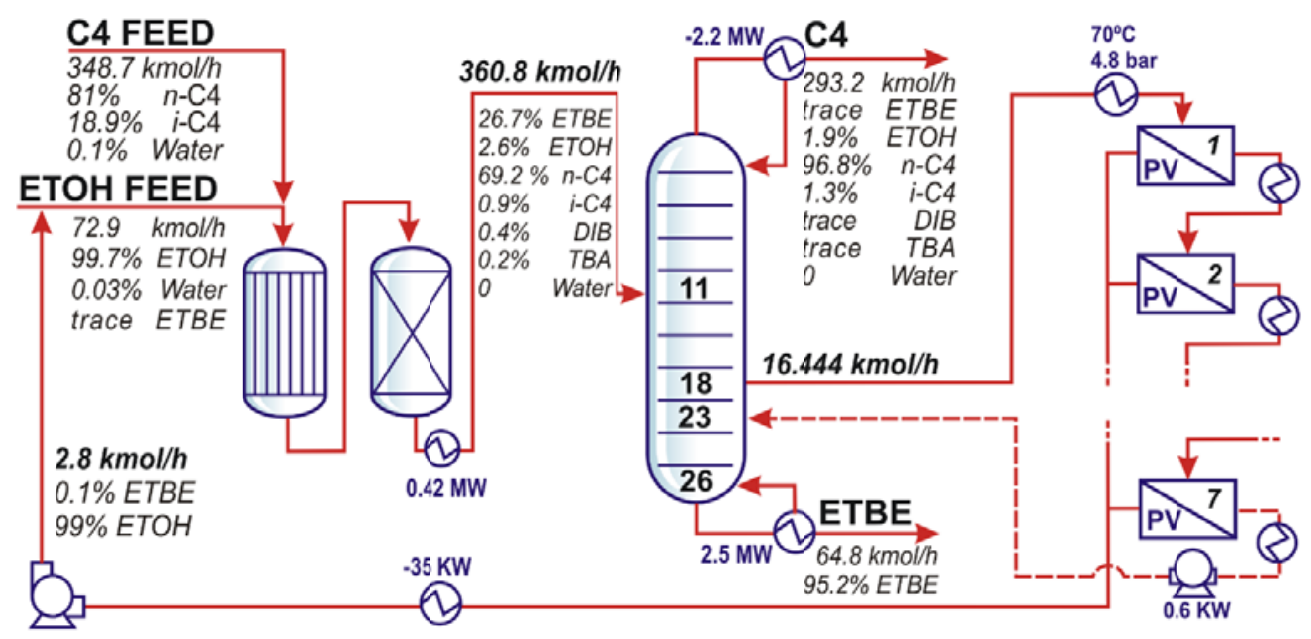

Table 1. Parameters of the pervaporation model for EtOH/ETBE mixtures permeating through PERVAP 2256 membrane $\left(65^{\circ} \mathrm{C}\right)$

\begin{tabular}{c|c|c|c}
\multirow{2}{*}{} & \multirow{2}{*}{ EtOH } & \multicolumn{2}{|c}{ ETBE } \\
\cline { 3 - 4 } & & $\mathrm{X}_{\mathrm{ETBE}}>0.78$ & $\mathrm{X}_{\mathrm{ETBE}}<0.78$ \\
\hline$A_{i}$ & $4.79 \times 10^{-3}$ & $8.61 \times 10^{-3}$ & $7.57 \times 10^{-4}$ \\
\hline$B_{i}$ & 0.186 & $-4.04 \times 10^{-4}$ & $-3.03 \times 10^{-4}$ \\
\hline$C_{i}$ & 8.208 & $-1.43 \times 10^{-4}$ & $-7.08 \times 10^{-4}$ \\
\hline$E_{\text {act, } i}\left(\mathrm{~kJ} \mathrm{~mol}^{-1}\right)$ & -3.35 & \multicolumn{2}{|c}{-3.91}
\end{tabular}

This article is protected by copyright. All rights reserved. 
Table 2. Summary of material balances for the 3 hybrid processes.

\begin{tabular}{|c|c|c|c|c|c|c|}
\hline \multicolumn{7}{|c|}{ Case A, Pervaporation before to distillation. Membrane area: $660 \mathrm{~m}^{2}$} \\
\hline & $\begin{array}{l}\text { Total } \\
\text { feed to } \\
\text { reactor } \\
\left(\mathrm{kmol} \mathrm{h}^{-1}\right)\end{array}$ & $\begin{array}{c}\text { Reaction } \\
\text { outlet } \\
\left(\mathrm{kmol} \mathrm{h}^{-1}\right)\end{array}$ & $\begin{array}{c}\text { Total } \\
\text { Retentate } \\
\left(\mathrm{kmol} \mathrm{h}^{-1}\right)\end{array}$ & $\begin{array}{c}\text { Total } \\
\text { Permeate } \\
\left(\mathrm{kmol} \mathrm{h}^{-1}\right)\end{array}$ & $\begin{array}{c}\text { Btm.1 } \\
\text { ETBE } \\
\text { product } \\
\left(\mathrm{kmol} \mathrm{h}^{-1}\right)\end{array}$ & $\begin{array}{c}\text { Dist.1 } \\
\text { C4 stream } \\
\left(\mathrm{kmol} \mathrm{h}^{-1}\right)\end{array}$ \\
\hline ETBE & 0.295 & 59.89 & 59.59 & 0.295 & 59.59 & 0.002 \\
\hline ETOH & 72.66 & 13.07 & 10.81 & 2.26 & 3.285 & 7.53 \\
\hline 1-butene & 282.68 & 282.68 & 282.68 & & $<0.001$ & 282.68 \\
\hline Isobutene & 66.06 & 3.97 & 3.97 & & trace & 3.97 \\
\hline TBA & & 0.763 & 0.763 & & 0.761 & 0.002 \\
\hline Water & 0.763 & & & & & \\
\hline DIB & & 0.865 & 0.865 & & 0.865 & trace \\
\hline Total & 422.46 & 361.24 & 358.68 & 2.56 & 64.5 & 294.18 \\
\hline $\mathrm{T}\left({ }^{\circ} \mathrm{C}\right)$ & 72.5 & 46 & 69.9 & 69.9 & 154.1 & 60.4 \\
\hline P (bar) & 10 & 10 & 6.4 & 0.026 & 8.43 & 7.84 \\
\hline
\end{tabular}

Case B, Distillation followed by pervaporation (distillate stream). Membrane area: $\mathbf{2 4 0} \mathbf{~ m}^{\mathbf{2}}$

\begin{tabular}{|c|c|c|c|c|c|c|}
\hline & $\begin{array}{l}\text { Total } \\
\text { feed to } \\
\text { reactor } \\
\left(\mathrm{kmol} \mathrm{h}^{-1}\right)\end{array}$ & $\begin{array}{c}\text { Reaction } \\
\text { outlet } \\
\left(\mathrm{kmol} \mathrm{h}^{-1}\right)\end{array}$ & $\begin{array}{c}\text { Btm.1 } \\
\text { ETBE } \\
\text { product } \\
\left(\mathrm{kmol} \mathrm{h}^{-1}\right)\end{array}$ & $\begin{array}{c}\text { Dist.1 } \\
\text { C4 } \\
\text { stream } \\
\left(\mathrm{kmol} \mathrm{h}^{-1}\right)\end{array}$ & $\begin{array}{c}\text { Total } \\
\text { Retentate } \\
\left(\mathrm{kmol} \mathrm{h}^{-1}\right)\end{array}$ & $\begin{array}{c}\text { Total } \\
\text { Permeate } \\
\left(\mathrm{kmol} \mathrm{h}^{-1}\right)\end{array}$ \\
\hline ETBE & 0.14 & 59.73 & 59.59 & 0.142 & 0.002 & 0.14 \\
\hline ETOH & 72.66 & 13.07 & 3.29 & 9.78 & 8.93 & 0.851 \\
\hline 1-butene & 282.68 & 282.68 & $<0.001$ & 282.68 & 282.68 & \\
\hline Isobutene & 66.06 & 3.97 & trace & 3.97 & 3.97 & \\
\hline TBA & & 0.763 & 0.758 & 0.005 & 0.005 & \\
\hline Water & 0.763 & & & & & \\
\hline DIB & & 0.865 & 0.865 & $<0.001$ & $<0.001$ & \\
\hline Total & 422.30 & 361.08 & 64.5 & 296.58 & 295.59 & 0.992 \\
\hline $\mathrm{T}\left({ }^{\circ} \mathrm{C}\right)$ & 72.5 & 46 & 154.1 & 60.5 & 69.9 & 69.9 \\
\hline P (bar) & 10 & 10 & 8.43 & 7.85 & 8.52 & 0.026 \\
\hline
\end{tabular}

Case C, Distillation followed by pervaporation (side stream). Membrane area: $\mathbf{2 1 0} \mathbf{~ m}^{\mathbf{2}}$

\begin{tabular}{|c|c|c|c|c|c|c|c|}
\hline & $\begin{array}{l}\text { Total } \\
\text { feed to } \\
\text { reactor } \\
\left(\mathrm{kmol} \mathrm{h}^{-1}\right)\end{array}$ & $\begin{array}{c}\text { Reaction } \\
\text { outlet } \\
\left(\mathrm{kmol} \mathrm{h}^{-1}\right)\end{array}$ & $\begin{array}{c}\text { Btm.1 } \\
\text { ETBE } \\
\text { product } \\
\left(\mathrm{kmol} \mathrm{h}^{-1}\right)\end{array}$ & $\begin{array}{c}\text { Dist.1 } \\
\text { C4 } \\
\text { stream } \\
\left(\mathrm{kmol} \mathrm{h}^{-1}\right)\end{array}$ & $\begin{array}{c}\text { Side } \\
\text { stream } \\
\left(\mathrm{kmol} \mathrm{h}^{-1}\right)\end{array}$ & $\begin{array}{c}\text { Total } \\
\text { Retentate } \\
\left(\mathrm{kmol} \mathrm{h}^{-1}\right)\end{array}$ & $\begin{array}{c}\text { Total } \\
\text { Permeate } \\
\left(\mathrm{kmol} \mathrm{h}^{-1}\right)\end{array}$ \\
\hline ETBE & 0.017 & 59.81 & 59.797 & $<0.001$ & 8.80 & 8.78 & 0.017 \\
\hline ETOH & 72.66 & 12.87 & 3.377 & 6.76 & 7.37 & 4.64 & 2.733 \\
\hline 1-butene & 282.68 & 282.68 & 0.001 & 282.68 & 0.073 & 0.073 & \\
\hline Isobutene & 66.06 & 3.767 & $<0.001$ & 3.767 & 0.001 & 0.001 & \\
\hline TBA & & 0.763 & 0.76 & 0.004 & 0.143 & 0.143 & \\
\hline Water & 0.763 & & & & & & \\
\hline DIB & & 0.865 & 0.865 & trace & 0.063 & 0.063 & \\
\hline Total & 422.18 & 360.75 & 64.8 & 293.21 & 16.444 & 13.69 & 2.75 \\
\hline $\mathrm{T}\left({ }^{0} \mathrm{C}\right)$ & 73 & 46 & 154.4 & 60.3 & 137.4 & 65.6 & 66.6 \\
\hline P (bar) & 10 & 10 & 8.43 & 7.85 & 8.25 & 4.78 & 0.026 \\
\hline
\end{tabular}


Table 3. Energy use details for each hybrid process configurations

\begin{tabular}{lccc}
\hline & Case A & Case B & Case C \\
\hline $\begin{array}{l}\text { Low pressure } \\
\text { steam }\end{array}$ & 3.19 & 2.39 & 0.67 \\
\hline $\begin{array}{l}\text { Middle pressure } \\
\text { steam }\end{array}$ & 2.82 & 2.88 & 2.92 \\
\hline $\begin{array}{l}\text { Total hot utilities, } \\
\text { MW }\end{array}$ & 6.01 & 5.27 & 3.59 \\
\hline $\begin{array}{l}\text { Cooling water } \\
\text { Refrigerant }\end{array}$ & 3.27 & 3.33 & 3.33 \\
\hline $\begin{array}{l}\text { Total cold } \\
\text { utilities, MW }\end{array}$ & 0.03 & 0.012 & 0.04 \\
\hline
\end{tabular}

